\title{
La atención a las víctimas de prostitución forzada durante el conflicto armado interno en el posacuerdo ${ }^{1}$
}

https://doi.org/10.21830/9789585241480.04

\author{
Paola Alexandra Sierra-Zamora ${ }^{2}$ \\ Ángela María Medina Carrión ${ }^{3}$ \\ Universidad Católica de Colombia \\ Manuel Bermúdez-Tapia ${ }^{4}$ \\ Universidad Privada San Juan Bautista \\ Juan Carlos Aristizábal Murillo 5
} Centro de Misiones Internacionales y Acción Integral

1 Este capítulo hace parte de los resultados del proyecto de investigación "Desafíos contemporáneos para la protección de derechos humanos en escenarios de posconflicto desde enfoques interdisciplinarios - FASE II" del Grupo de Investigación Persona, Instituciones y Exigencias de Justicia, del Centro de Investigaciones Sociojurídicas, Facultad de Derecho, de la Universidad Católica de Colombia, registrado con el código COL0120899 de Minciencias. También contó con la colaboración de los siguientes proyectos de investigación: "Análisis del perfil criminológico de adolescentes infractores para evaluar tasas de reincidencia delictiva que afecte la seguridad ciudadana”, aprobado por Resolución Vicerrectoral No 058-2018-VRIUPSJB de la Universidad Privada San Juan Bautista, Perú; y "Modelo de enseñanza-aprendizaje en (DDHH) Derechos Humanos y (DIH) Derecho Internacional Humanitario en el Ejército Nacional de Colombia a través del juego y la simulación" del Grupo de Investigación del Centro de Misiones Internacionales y Acción Integral (CEMAI). Los puntos de vista y los resultados de este capítulo pertenecen a los autores y no reflejan necesariamente los de las instituciones participantes.

2 Abogada de la Universidad Católica de Colombia. Magíster en Derechos Humanos, Democracia y Justicia Internacional por la Universitat de València, España. PhD (c) del Programa de Derechos Humanos, Democracia y Justicia Internacional por la Universitat de València, Espańa. Investigadora del Grupo de Investigación en Ciencias Militares de la Escuela Militar de Cadetes "General José María Córdova”. Orcid: https:// orcid.org/0000-0002-3146-7418. Contacto: paola.sierra@esmic.edu.co

3 Estudiante de la Facultad de Derecho de la Universidad Católica de Colombia y miembro del semillero de investigación "Observatorio de justicia constitucional de derechos humanos", vinculado al Grupo de Investigación Persona, Instituciones y Exigencias de Justicia, de la Universidad Católica de Colombia.

4 Abogado (magna cum laude) de la Pontificia Universidad Católica del Perú. Profesor-investigador de la Universidad Privada San Juan Bautista y profesor de la Facultad de Derecho de la Universidad Nacional Mayor de San Marcos. Consultor en temas de reforma del sistema de justicia en el Perú para el Banco Mundial, el Congreso de la República, el Poder Judicial y la Academia de la Magistratura. Orcid: https://orcid.org/0000-00031576-9464. Contacto: manuel.bermudez@upsjb.edu.pe

5 Magíster en Administración Educativa y Políticas Públicas y especialista en Docencia e Investigación Universitaria de la Universidad Sergio Arboleda. Administrador de empresas de la Universidad Militar Nueva Granada y profesional en Ciencias Militares de la Escuela Militar de Cadetes "General José María Córdova”. Orcid: http://orcid.org/0000-0002-3690-3282. Contacto: juanaristizabalmurillo@cedoc.edu.co 


\section{Resumen}

El conflicto armado es una crisis que afecta a Colombia desde hace más de cincuenta años. Con el proceso de paz, el contexto empieza a tomar otro rumbo, pero hay un tema que no se expone en su real dimensión: la prostitución forzada de mujeres provocada por las acciones de los grupos insurgentes en sus zonas de influencia. Para el debido análisis de esta problemática es necesario tomar elementos referenciales que permitan comprender las propuestas del Acuerdo de Paz en la perspectiva los derechos de las mujeres.

De forma complementaria, se debe tener en cuenta que la mujer en la actualidad toma las riendas de su propio destino y empieza a ser constructora de su propia historia, artífice y garante de su proyecto de vida en libertad, tras la superación de la vida en confinamiento en las selvas colombianas. Situación que debe atender y garantizar el Estado.

Palabras clave: derechos humanos; género; mujer; proceso de paz; prostitución forzada; territorio

\section{Introducción}

La problemática del conflicto armado interno en Colombia ha sido un tema trascendental durante años, teniendo en cuenta que ha dejado millones de víctimas, sin discriminación alguna a sexos, razas ni clases sociales (SierraZamora, 2018). Esta confrontación ha ocasionado graves secuelas, como la lucha interminable contra el narcotráfico, la venta de drogas a nivel masivo, el desplazamiento forzado y el reclutamiento de menores, entre otras. En este mismo sentido, las mujeres han sido víctimas desde la parte activa del conflicto armado, en donde la violación de derechos humanos ha sido más que recurrente, puesto que desde muy pequeñas se ven envueltas en prostitución y demás crímenes de lesa humanidad (Cubides-Cárdenas et al., 2017).

Entiéndase como crímenes de lesa humanidad los ataques generalizados a la población civil, como el secuestro, el exterminio, la violación, etc. Esta problemática se convierte en el objeto principal de atención del Estado colombiano hasta la fecha (Tokatlian, 2001), teniendo en cuenta el Acuerdo Final para la Paz, que centra su atención en las mujeres mediante el enfoque de género y la reparación integral como víctimas; no obstante, la realidad que vivieron y viven diariamente estas mujeres víctimas es otra.

Como metodología de análisis, se tomó la investigación cualitativa, que se basa en construir, naturalizar, unificar y analizar distintos puntos de vista, 
teorías y doctrinas, con el fin de construir nuevos conceptos para la transformación y desarrollo de ideales, conceptos y estrategias novedosas. Este tipo de investigación atañe a todo lo social, pues le permite al investigador una observación determinada y centrada, para producir conocimientos desde el interior de la realidad que él también vive (Palacios Gómez, 2001).

Por lo tanto, el presente capítulo se va a desarrollar mediante la metodología de investigación cualitativa-propositiva (Palacios Gómez, 2001), con el objetivo de analizar las ejecuciones de los mecanismos de control y defensa sobre la problemática de prostitución. De acuerdo con esto, se impone el siguiente interrogante: ¿Cómo se ejecuta el mecanismo de protección internacional frente a la prostitución forzada que se ha identificado en el posconflicto?

Para el desarrollo del capítulo se establecieron tres ejes temáticos: inicialmente, se identifican las generalidades del término prostitución, con lo cual se define claramente el concepto de prostitución forzada, con el fin de analizar las distintas perspectivas doctrinales que se tienen con respecto este. En un segundo momento, se analizan los mecanismos internacionales de protección de los derechos de las mujeres respecto del tratamiento que se evalúa en el derecho comparado, en particular, los mecanismos de protección de la mujer en Colombia. En una tercera etapa, se analiza el Acuerdo Final para la Paz frente la problemática de la prostitución. A manera de cierre, se presentan unas breves conclusiones.

\section{Conceptualización del término prostitución}

La Sentencia T-736-15 define la prostitución como el reconocimiento a personas discriminadas que, por decisión propia u obligada, trabajan con su cuerpo en actividades que atentan contra su dignidad humana, igualdad y principios (T-736, 2015). Aunque no está reglamentada, la Sentencia T-629-10 profiere que la prostitución no es ilegal y, aunque en algún momento lo fue, esta hoy no es un delito, pero tampoco está regulada. Esto impide que las trabajadoras sexuales gocen de los beneficios de un trabajo común y corriente que, ante los ojos de la ley, es merecedor de todas las prestaciones sociales (T-629, 2010). 
Teniendo esto en cuenta, la práctica de la prostitución en Colombia se ha vuelto un tema de gran relevancia, pues muchas mujeres se dedican a ello, pero sus derechos laborales no son reconocidos (Betancourt y Cortés, 2011). Por otra parte, están los casos de abuso en el contexto del conflicto armado interno, pues dentro de este muchas mujeres, en su mayoría campesinas, sufrieron la prostitución forzada por parte de distintos grupos al margen de la ley, en este caso, las FARC-EP (Cubides et al., 2019).

En efecto, el conflicto armado colombiano tiene "cuerpo de mujer", dado el sometimiento a distintas torturas a la población vulnerable, lo cual es inaceptable puesto que está directamente relacionado con la violación de derechos humanos, como la dignidad humana, el derecho a la vida, al buen nombre, al trabajo digno, a la libertad, etc. (Garay Acevedo y Pérez Guecha, 2018; Sierra-Zamora y Jiménez-Barrera, 2019).

En Colombia, según el registro único de víctimas (RUV), entre marzo de 1985 y enero de 2013, se contabilizaron 2683355 mujeres víctimas directas del conflicto. De este total, se destaca un grupo de 489687 mujeres que fueron víctimas de violación y prostitución forzada (Cadavid, 2014). Con base en estos datos puntuales, la presente investigación se centrará en el segundo grupo, por lo que se deben tener en cuenta estas cifras en adelante para el desarrollo de la presente investigación.

Estas estadísticas permiten identificar que las víctimas no pueden ser "medidas" por casos de desaparecimiento o porque registran alguna denuncia vinculada al proceso del conflicto armado interno, pues hay muchas mujeres que por miedo aun callan esta atosigante verdad, verdad que solo es consecuencia del conflicto armado, que es el resultado de una democracia débil que siempre ha tenido el país. En la problemática de afectación a la mujer, como sujeto de derechos y como grupo poblacional, Bermúdez-Tapia detalla que ellas pueden ser víctimas en tres niveles:

a. A nivel individual, especialmente porque contra su persona se han ejecutado acciones lesivas que han atacado su dignidad, integridad y derechos.

b. A nivel colectivo, especialmente porque no son consideradas en un nivel o plataforma equivalente a otros grupos poblacionales en comparación con el sector masculino de la población nacional. 
c. A nivel difuso, en particular porque el Estado desarrolla de modo negligente sus políticas públicas sin lograr equiparar los derechos a nivel individual y colectivo de varones y mujeres. En este punto, es posible observar que las acciones en el ámbito de los servicios de educación, salud, de promoción laboral o atención de emergencias sociales, no está debidamente atendido para la mujer como grupo poblacional (Bermúdez-Tapia, 2012).

Consecuentemente surge una serie de situaciones que amplía el margen negativo hacia las mujeres, y que se convierte en un problema nacional cuando se analiza el contexto de atención a las mujeres sometidas a prácticas de prostitución durante el conflicto armado interno. Tales situaciones evidencian el escaso nivel de atención en este punto con el que ha contado la comunidad y las escasas acciones de la administración pública al respecto.

Y no solo allí radica el problema, este también ha sido fiel al resultado de una sociedad que creó hombres listos para la guerra, pero, a consecuencia de esta, más de dos millones de mujeres tuvieron que reflejar estas atrocidades usando como espejo sus vidas y las de sus familias enteras. El resultado de esta situación es un problema que afecta a la población en general, pero en especial a las sobrevivientes, muchas de las cuales se consideran muertas espiritualmente, porque ninguna reparación podría aliviar el daño que se les ha provocado.

La prostitución forzada en Colombia es una violencia fundamentada en una cultura machista, dentro de la cual, los hombres suponen que tienen el poder de sometimiento sobre las mujeres, pues las consideran inferiores bajo un concepto similar al de propiedad. Esta ideología solo ha cobrado vidas de personas que nada tienen que ver con ello, de personas que no quisieron ir la guerra, pero les tocó vivirla (Casado-Neira y Pérez, 2015).

La región donde se registra una mayor incidencia de este problema social es Medellín, pues según estadísticas del RUV, la mayor parte de las víctimas se registran allí. Por ser una zona de conflicto constante, allí se da la primera clasificación de las víctimas. Las víctimas directas son objeto de torturas, desplazamiento forzado y violencia sexual, mientras que las víctimas indirectas son 
los familiares que sufren la muerte, el secuestro, la desaparición y en desplazamiento de sus parientes más cercanos, los cuales son obligados a abandonar sus tierras y a empezar de cero en lugares en los que no conocen a nadie (Ibáńez y Querubín, 2004).

\subsection{Los mecanismos de protección internacional frente a situaciones de práctica ilegal de la prostitución}

Esta problemática dejó a grandes rasgos, crisis sociales que reincidieron a nivel internacional; tanto así que las convenciones internacionales influenciadas por la ONU han sido artífices de distintos tratados para la mujer, dentro de los cuales se ha visto desde el punto de vista de los derechos humanos, la intervención de distintos entes controladores generadores de acuerdos (Heim, 2011).

Sin embargo, pese a la persistencia del problema, no fue sino hasta los años noventa del siglo pasado que distintos comités internacionales decidieron formular acciones contra este fenómeno. Por consiguiente, vale la pena hacer una breve revisión histórica de los distintos y más importantes acuerdos al respecto desde 1904 hasta el último tratado vigente de la ONU en 2014:

a. $\quad$ El primer acuerdo se genera en 1904: "Acuerdo internacional para la supresión del tráfico de trata de blancas, prostitución y violación de derechos humanos", firmado en París, con el fin de intervenir y asegurar los distintos derechos de niños, niñas y adolescentes que estaban siendo traficados con propósitos lucrativos. Este acuerdo solo obtiene la firma de 69 países americanos y su objetivo es garantizar los derechos de las distintas víctimas de esta barbarie (ONU, 1904).

b. El segundo tratado internacional, firmado en 1950, se titula "Convenio internacional para la represión de trata de blancas y la exportación de prostitución ajena”. Este se enfoca en la prohibición de las distintas formas de tráfico, de forma que establece distintas medidas de prevención y destinación de fondos a organizaciones que se encarguen de personas que han sido tratadas para la restauración de sus derechos (Garbay, 2004). 
c. El tercer tratado internacional, firmado en 1973, se titula "Convenio internacional sobra la eliminación de todas formas de discriminación contra la mujer”. Este documento es uno de los más importantes de la historia, puesto que tiene como eje no solo las víctimas de prostitución, sino a las mujeres que se dedican a este oficio por voluntad propia. Este convenio exige igualdad de derechos para las mujeres sin importar las distintas actividades a las cuales estas puedan dedicarse. Cuenta con la firma de más de 100 países, incluido Colombia, y se refiere a derechos humanos específicos como los derechos reproductivos y el derecho al trabajo (Naciones Unidas, 2014).

d. El cuarto tratado internacional, firmado en 1995, se titula "Plataforma de acción en Beijing", que se enfoca en la trata de mujeres y la prostitución forzada, la reivindicación y garantía de los derechos humanos a mujeres vulneradas, las distintas concepciones de género y la importancia de la igualdad (Checa y Acién, 2011).

e. Finalmente, está la quinta y última asamblea general del Consejo Económico y Social Mundial, la Comisión de Derechos Humanos y la Comisión de Condición Jurídica y Social de la Mujer, 2009, titulada "Relatoría especial sobre la violencia contra las mujeres y las niñas, sus causas y consecuencias". Este documento tiene en cuenta todas las cumbres anteriores, detalla sus modificaciones y reconsidera las distintas concepciones del tráfico de mujeres y su evolución en la sociedad. A partir de ello, toma medidas contundentes, como el compromiso de los gobiernos a nivel nacional e internacional contra el tráfico de menores, el establecimiento de políticas en contra del crimen y el total resguardo de los distintos derechos de las mujeres, con el fin de garantizarles, desde su nacimiento, una vida equitativa, educación y protección. Esta relatoría, a la fecha, sigue vigente (Wilson, 1999).

Teniendo en cuenta lo anterior, se puede tener una idea clara de los distintos mecanismos internacionales de protección para la mujer víctima de prostitución, problema que cuenta con más de 100000 mujeres afectadas 
anualmente (Castellanos et al., 2013). El desconocimiento de estos mecanismos hace que las víctimas piensen que están solas y que, desde la visión de un gobierno casi ausente en esta problemática, tengan miedo de denunciar porque piensan que será peor.

Según el movimiento Amnistía Internacional, las trabajadoras sexuales, forzadas o no, son enfrentados a discriminación constante y violación de derechos fundamentales (Amnistía Internacional, 2015), dentro de los cuales están la "violación del derecho a la dignidad, violación del derecho a la paz, violación del derecho a la libertad sexual, violación de distintos derechos civiles”. Todo ello está contemplado por la Corte Interamericana de Derechos Humanos, como lo consagra en su "Convención interamericana para prevenir, sancionar y erradicar la violencia contra la mujer (Convención de Belem do Para)”:

Artículo 2: se entenderá que la mujer sufre violencia tanto física y sexual como psicológica.

[...].

Artículo 5: toda mujer podrá ejercer sus derechos con total libertad, tanto civiles como laborales, sin temor a ser rechazada.

[...].

Artículo 7: las mujeres víctimas de tráfico humano con fines de prostitución, tendrán que ser cobijadas por privilegios que restituyan sus derechos vulnerados, como lo son: tratamiento psicológico por el tiempo que lo requiera, alimentación y atención médica, preparándola así para reincorporarse a la vida social

Los mecanismos de defensa internacional son una realidad que se le atribuye a los distintos países que hacen parte de estos convenios, mas, sin embargo, por el desconocimiento y la impopularidad de estos, logra que las víctimas no recurran a ellos, ya que son casi como un misterio en medio de un estado ausente que no les propicia un ambiente seguro ni siquiera para prever estas situaciones (Castles, 2003).

\subsection{Mecanismos de protección nacional frente a casos de prostitución femenina individual o colectiva}

Además de los acuerdos internacionales, Colombia como Estado de derecho tampoco ha sido indiferente a estas violaciones a los derechos humanos 
y cuenta con una normatividad jurídica llena de garantías y protección para las víctimas (Clark, 2001). La prostitución en el conflicto armado hace que la historia tenga un matiz triste, pues niñas y mujeres fueron reclutadas y obligadas a desempeñar estas funciones con fines lucrativos y para satisfacer los caprichos de los cabecillas de los insurgentes (Daich, 2012).

El eje de enfoque es, que, aunque existen miles de víctimas, el estado reglamenta de alguna manera las sanciones pertinentes para los victimarios y para las víctimas, garantías de protección y demás. Aunque Colombia es un país comprometido en la mayoría de los tratados internacionales, es paradójico que el gobierno no ponga su atención en estos temas tan relevantes que han aquejado el país por más de una década (Varón-Mejía et al., 2012).

Una de las regulaciones nacionales más importantes respecto de la prostitución forzada es la Constitución Política de Colombia que, en su artículo 17, prohíbe toda clase de esclavitud, servidumbre y trata de seres humanos con distintos fines (Constitución Política de Colombia, 1991). El Congreso de la República, por su parte, en el 2005 promulga la Ley 985 de 2005, la cual vela por las medidas de protección para las personas que han sido víctimas de prostitución forzada, dentro de los cuales acentúa los mecanismos de reacción inmediata y los privilegios con los que pueda contar esta víctima (Congreso de la República, 2005).

La Corte Constitucional, en la Ley 765 de 2002, promueve el "Protocolo facultativo de la convención de los derechos de la mujer, relativos a la venta, prostitución y pornografía”, mediante la Sentencia C-318 de 2003. Esta ley se encarga de tener como objeto distintas prohibiciones a la venta de niños y mujeres, y tiene efectos internacionales, es decir, gracias a ella se puede operar sobre territorio extranjero en búsqueda de un nacional (Corte Constitucional, 2003).

Ante la existencia pero poca eficacia de estas leyes, mediante esta investigación se dan a conocer las convenciones de las cuales forma parte el país:

a. "Convención sobre la eliminación de todas las formas de discriminación contra la mujer" (1981): por medio de este documento, el Estado se compromete a impulsar medidas de construcción social 
y cultural con el objeto de reivindicar y estimular el respeto hacia la mujer, así como alejarla de cualquier discriminación que afecte de cualquier manera el desarrollo de sus facultades como persona y de sus derechos (Binstock, 1998).

b. "Protocolo facultativo de la Convención de los Derechos del Niño relativo a la venta, la prostitución y pornografía infantil, 2000”, cuyos artículos establecen, entre otras: definiciones de los distintos delitos (art. 3), extraterritorialidad y acción de autoridad nacional en el extranjero (arts. 4 y 5). (Asamblea General de las Naciones Unidas, 2002).

La autoridad estatal, aunque se ha encargado de regular, permanece ausente en la mayoría de estos casos. Pese a su fuerte conexión con los distintos tratados internacionales, la víctima puede sentir una falta de protección por parte del gobierno nacional. La carencia de control en este aspecto deja mucho que desear de parte de los dirigentes y las medidas que se les atribuyen como reacción ante estas situaciones (Garavito et al., 2012).

\subsection{La legislación y jurisprudencia nacionales frente al problema de la prostitución forzada}

Dentro de las leyes nacionales enfocadas en la atención ejemplar de víctimas de violencia en el marco del conflicto armado con énfasis en la violencia sexual se encuentran las siguientes: Ley 1235 de 2008, mediante la cual se garantiza para todas las mujeres una vida libre de violencia, tanto en el ámbito público como en el privado, el derecho de acceder a políticas públicas y su respectiva realización; y la Ley 1450 de 2011, que garantiza los derechos humanos integrales e independientes de las mujeres y la igualdad de género, teniendo en cuenta las particularidades y la población indígena.

De la Corte Constitucional, por su parte, se destacan algunas referencias de la jurisprudencia (autos y sentencias), las cuales tienen que ver directamente con la violencia de género, la prostitución y el conflicto armado:

a. Propone la protección de los derechos fundamentales de las mujeres desplazadas por el conflicto armado en el país y previene el impacto de 
género desproporcional del conflicto Auto 092-2008: armado y el desplazamiento forzado.

b. Auto 237-2008: Adopción de medidas para la protección de mujeres víctimas del desplazamiento forzado por causa del conflicto armado, por medio de las cuales se caracterizan los efectos del desplazamiento forzado y da respuesta a la falta de apoyo del gobierno sobre estos aspectos.

c. Auto 098-2013: Seguimiento de las acciones gubernamentales respecto a la prevención, protección y seguridad de mujeres líderes, víctimas del conflicto armado (Corte Constitucional, 2019).

d. T-234 de 2012: Dentro de esta providencia se estudia el caso de una defensora de derechos humanos que ha sido víctima de violencia sexual y desplazamiento forzado. La Corte establece que existe una condición de vulnerabilidad manifiesta de la mujer, debido a la sociedad patriarcal que ha reforzado la discriminación histórica contra las mujeres, por lo cual las defensoras de derechos humanos deben gozar de una protección reforzada. Aquí se especifica el deber del Estado colombiano de brindar medidas de protección a las personas que se dedican a la defensa de los derechos humanos con un enfoque de género, atendiendo el impacto diferenciado que se presenta hacia las mujeres en el conflicto armado (Olaya, 2004).

e. C-400 de 2003: Mediante esta sentencia se determinó la constitucionalidad de la Ley 589 de 2000 en su artículo 10, $\$ \$ 1$ y 2. Se consideraron constitucionales los tipos penales de genocidio, desaparición forzada, desplazamiento forzado y tortura (Vela Caro, 2015).

f. T-496 de 2008: Establece el derecho a la seguridad personal, respaldado por los artículos 93 y 94 de la Constitución, los que brindan la investidura de derecho fundamental a todos aquellos relacionados con la mujer. La sentencia indica su condición de sujetos de especial protección y parte de la Ley 975 de 2005, también conocida como Ley de Justicia y Paz (Guío Camargo, 2009).

g. C-781 de 2012: Reitera los derechos de las víctimas a la verdad, la justicia y la reparación, además de precisar el deber de examinar por parte del operador jurídico en cada caso concreto las circunstancias en que se haya producido una grave violación de los derechos humanos o del derecho internacional humanitario y el contexto en que ocurrieron los hechos para determinar la relación cercana y suficiente con el conflicto armado interno (Durango Álvarez, 2012).

Como se evidencia, a pesar de que Colombia se ha preocupado por regular todas estas conductas ilegales, han habido circunstancias de indiferencia ante muchas situaciones, bien por ausencia de conocimiento, bien por el miedo a la denuncia (Tirado Acero, 2011). 


\section{Trascendencia de la mujer en el conflicto y posacuerdo}

En Colombia, existen distintos tipos de conflicto armado encabezados por las FARC, la cual fue la guerrilla más grande y la que hizo un proceso de paz encaminado hacia la erradicación permanente del conflicto (Ibarra Melo, 2011; Torrijos Rivera y Abella Osorio, 2018). Dentro de esta guerrilla, el rol de la mujer se hace bastante importante, ya que al principio solo se reclutaban hombres con el fin de tener un ejército fuerte capaz de combatir, pero con el tiempo los intereses de los guerrilleros se fueron ampliando, de tal manera que el reclutamiento empezó a abarcar a las mujeres desplazadas, sin importar la edad. Esto con el fin de satisfacer no solo necesidades de apoyo — por ejemplo, en la preparación de la comida—, sino también poder satisfacer sus deseos sexuales de manera indiscriminada (Zuluaga-Sánchez, 2013).

$\mathrm{Al}$ ser recluidas, estas mujeres (en su mayoría del campo) empiezan a sufrir los horrores de la guerra, dentro de los cuales tienen que soportar, entre otros, balaceras, estar listas para el combate, cocinar para todos, ser mensajera, comunicadora, distractora, contadora, enfermera, etc. En efecto, a ellos les convenía tener mujeres que ayudaran a mantener este círculo económico interno, sostenible para cada uno de sus integrantes (Pinzón Paz, 2009).

Durante el desempeño de sus distintas actividades, un porcentaje importante de mujeres era destinado a labores de prostitución forzada con fines lucrativos en zonas aledañas a los frentes de combate. Los cabecillas vestían a las mujeres de manera mediante la cual pudieran ser identificadas por el grupo en guardia que la iba a llevar. Luego de esto, el dinero producido por aquella mujer era tomado por sus acompañantes y entregado directamente al comandante del frente, con el fin de destinar esos fondos a la manutención del grupo (Caicedo, 2008).

Las experiencias de violencia de estas mujeres y los constantes vejámenes a los que fueron sometidas son indescriptibles y, aun así, siguen en búsqueda de luces de esperanza en donde puedan encontrar un camino hacia la libertad; dolor y sufrimiento son las palabras que mejor describen las distintas historias. Sin embargo, esa mujer quedó en el pasado cuando se abrió el proceso 
de paz del 2012, un proceso que les permite soñar más allá de una selva, un proceso que les abre un puente entre una vida y la supervivencia diaria (Tirado Acero, 2011).

\subsection{Estadísticas sobre la mujer víctima del conflicto armado interno}

La Unidad para la Atención y Reparación Integral a las Víctimas (UARIV) identifica una totalidad de víctimas equivalentes a 7028776, de las cuales el 49,5\% son mujeres de distintas edades. La cifra que más escandalizó está en las niñas de 6 a 12 años, con un total de 455212 niñas recluidas en dichas edades. Es impresionante cómo estas pequeñas son llevadas al conflicto desde que no tienen noción, las crían a su manera y el producto es una mujer violada, vulnerada, escondida en un gran caparazón que le permite ser fuerte ante la sociedad, pero débil ante sus propios ojos (Berrío, 2013).

Las estadísticas son verdaderamente escalofriantes, más cuando la mayoría de las víctimas son nińas, que han vivido el conflicto sin conocer nada de la vida y cuya personalidad se forjó en un ambiente de guerra, dentro del cual muchas veces fue víctima de abusos, de atrocidades y de distintas maneras de tortura (Hernández y Gras, 2005).

Escuchar testimonios de algunas excombatientes, víctimas también de prostitución, resulta verdaderamente desgarrador, de lo que se puede deducir una práctica sistemática de la cual la violencia es protagonista. Dentro de la sociedad guerrillera solo existe una realidad: la de los hombres que se apropiaron de la vida de muchas mujeres como si fueran un objeto. Vivir el conflicto tan de cerca es vivir una guerra diaria, tanto contra el civil, como contra el policía y el soldado; es tener la incertidumbre de amanecer vivo o no, es el miedo constante a la agresión física, verbal y sexual. Es vivir soñando con un fin, es vivir con el sinsabor de no querer estar más en esa situación (Meertens, 1995).

\section{Rol de la mujer en el posacuerdo}

Las mujeres víctimas de prostitución y desplazamiento dentro del conflicto armado juegan un papel verdaderamente importante, ya que son 
ellas las artífices y el ejemplo de lo que puede suceder después de la guerra en un proceso de justicia y reparación, con el objeto y la decisión de reconstruir sus vidas (Grau, 2013). Uno de los puntos importantes para el acuerdo de paz es la habilidad con la que ellas se desenvuelven para la prevención y solución de conflictos, la disposición y decisión de rehacer sus vidas reubicándose y la facilidad para perdonar todo el daño causado durante tantos y tantos años (Gómez Suárez et al., 2017).

Pero hay algo que trasciende muchísimo más: la mirada del acuerdo de paz desde una perspectiva de género y de equidad, puesto que, según estadísticas del DANE, las FARC estaban conformadas en un $35 \%$ por mujeres. Los acuerdos de paz, en consecuencia, se ven en alta medida influenciados por las mujeres que vivieron día a día el conflicto armado no solo como prostitutas, sino como combatientes, cocineras y mensajeras (Suárez et al., 2016). Así, como enfoque principal de los acuerdos de paz en torno a la mujer, se tuvieron en cuenta los siguientes ejes principales:

1. Igualdad de condiciones en la restitución de tierras en caso de desplazamiento forzado. Acción que garantiza acceso a derechos económicos, culturales, de vivienda y salud.

2. Participación en resolución de conflictos, participación e instancias de decisión. Las formas de activismo en prevención y atención en casos de desmovilización y antecedentes de prostitución forzada constituyen la mejor manera de tutelar los derechos de aquellas mujeres afectadas por el conflicto armado interno que hubieran sido forzadas a ejercer la prostitución.

3. Adaptabilidad de medidas de protección que atienden los riesgos específicos de las mujeres.

4. El acceso equilibrado a la justicia, a la verdad, a garantías de reparación y de no repetición en las distintas formas dentro de las cuales la mujer fue agredida.

5. El reconocimiento integral y legal a distintas funciones en el poder público. (SOFIA, 2019)

Las mujeres víctimas exigieron también ser reconocidas por comités ante la JEP, ser reconocidas para desempeñar funciones en la prevención del conflicto, no ser reconocidas como víctimas sino como sobrevivientes y entendieron que el fin del conflicto era una oportunidad para trascender del dolor y ser tejedoras de cambio, tejedoras de paz (Alzañiz Moscardó, 2009) 
En este acápite, también se dieron distintos puntos mediante los cuales se fortalecen los tipos de participación que ejercerán las mujeres víctimas de prostitución y conflicto. A las mujeres campesinas, además, se le restablecerá su derecho al patrimonio mediante la reforma rural integral. Finalmente se enfatiza en los acuerdos específicos con las víctimas del conflicto (Almagro Iniesta, 2014). Esto solo demuestra la fortaleza de las tantas mujeres que, aunque víctimas de los dolores de la guerra, dan un paso adelante del dolor y siguen adelante, trabajando por sus hijos, por sus familias, por ellas mismas y, pese al abandono del Estado, por un país mejor.

\subsection{Los pilares importantes del proceso de paz y la influencia de la mujer}

Dentro del acuerdo de paz, las mujeres víctimas del conflicto se consideraron prioridad. De esta manera, se les dio la oportunidad de comenzar de nuevo y de tener una participación importante dentro de los acuerdos que cambiarían la historia colombiana: antes de los mecanismos de protección, existieron seis pilares de máxima importancia para la construcción del acuerdo (Fisas, 2010):

1. Programa de sustitución de cultivos de uso ilícito: Este pilar tiene como objetivo restaurar las posibilidades de vida de la mujer víctima y desplazada, oriunda del campo, darle la oportunidad de recuperar sus cultivos a cabalidad y dentro de la legalidad (Bremer, 2017).

2. Medidas de igualdad de género: Se estipula el fortalecimiento de la participación y las capacidades de organización de mujeres rurales para el apoyo de proyectos. Se garantiza la participación de la mujer en la planeación y ejecución para combatir cualquier tipo de violencia (Sauceda, 2015).

3. Comisión de la no repetición: El establecimiento de esta autoridad extrajudicial estará formada por once comisionarios, los cuales se encargarán de velar por la integridad del ciudadano, así como por la generación de un Estado responsable y activo, gracias a lo cual se ejercerán distintos criterios de selección basados en la inspiración de la confianza ciudadana (Arzú, 1999). 
4. Unidad de buisqueda de personas desaparecidas: Este órgano se encargará de la gestión, investigación y antecedentes con respecto a las personas declaradas como desaparecidas y, en caso de fallecimiento, la dignificación y restitución de derechos a las familias (Mesa, 2006).

5. Tratamiento especial: Este pilar se refiere a que las personas que hayan cometido delitos comprobados en el conflicto armado sean judicializadas de la manera debida y se le reconozca a la familia de la víctima una indemnización y ayuda psicológica durante el primer periodo.

6. Satisfacción de los derechos de las víctimas: Teniendo en cuenta las sanciones previstas, el Estado tendrá como deber principal restituir a las víctimas del conflicto, estudiar sus casos y evitar una repetición de estos crímenes atroces, por lo cual se tiene en cuenta el estudio permanente de comisiones especiales para la restitución transparente de dichos derechos (Oficina del Alto Comisionado para la Paz, 2016).

Estos pilares promueven el buen desarrollo de un acuerdo de paz equitativo, con la esperanza de compilar y generar equidad para las mujeres que fueron víctimas y también teniendo en cuenta a la desmovilizada, con el fin de buscar un acuerdo bilateral para la no repetición, el compromiso y la oportunidad de cerrar el capítulo de la guerra para siempre (Humanas, 2017).

\subsection{Mecanismos de protección a la mujer en el proceso de paz}

En la etapa de la elaboración del Acuerdo, teniendo en cuenta las habilidades de las mujeres para la prevención del conflicto, se contó de manera esencial con su papel en la reconstrucción social y la prevención de una posible repetición. Es un gran reto tanto para las víctimas como para las desmovilizadas mantener el margen del acuerdo, contando con el cumplimento de las dos partes (Sieder y Sierra, 2011).

La mujer líder social, víctima, exguerrillera, desmovilizada y ciudadana siempre será un punto fundamental para contar con la posibilidad de crecer y de reintegrarse a la vida social de la que un día fue arrebatada, tanto por opción 
propia como impuesta. Cada mujer cumple una gran función para hacer crecer la sociedad. En consecuencia, el proceso de paz colombiano, iniciado el 4 de septiembre de 2012, conforma una etapa crucial de la historia colombiana para terminar con la guerra interna del país, que ha registrado un periodo superior al medio siglo (Niño, 2017).

En el Acuerdo también se tienen en cuenta temas y aspectos importantes de la guerra y sus consecuencias, seis de los más importantes son los siguientes:

1. Políticas de desarrollo agrario integral, en donde se garantiza el restablecimiento de las funciones del campo, el cultivo y la restitución del derecho patrimonial a los desmovilizados oriundos.

2. Participación política: los exguerrilleros tendrán la oportunidad de ocupar cargos públicos con el fin de poder opinar sobre las decisiones del país y llevar a Colombia a un mejor futuro, por lo cual el Estado garantiza la facilidad y creación de partidos políticos independientes dirigidos y conformados por exguerrilleros.

3. El fin del conflicto: los victimarios tendrán la oportunidad de desmovilizarse y, mediante mecanismos estructurados de monitoreo, llegar a la reincorporación de la vida civil. La desmovilización abre puertas importantes a nivel político, pues quien se desmovilice tendrá la facilidad de ocupar cinco curules en la Cámara de Representantes y en el Senado.

4. Solución al problema de drogas ilícitas, por el cual se promueve la sustitución autónoma de cultivos ilícitos, reemplazándolos por cultivos que contribuyan al desarrollo de la nación, cultivando así en tierras fértiles todo lo que tenga que ver con agricultura legal (Mesa, 2014).

5. La reparación de víctimas en aras del sistema de verdad, justicia y mecanismos judiciales, para la creación del perdón, la no repetición y el poder seguir adelante. Este punto tiene por objeto la construcción de una sociedad reconciliada y reparada, dispuesta a salir adelante y a construir redes inquebrantables de respeto y tolerancia, libre de agresiones y de amenazas. 
6. Implementación, reparación y refrendación. Esta será una comisión dedicada a hacer seguimientos sobre el cumplimiento del acuerdo, también velará por el impulso de las distintas normas legislativas y la transparencia del acuerdo de paz en ejecución (Céspedes-Báez, 2017).

Entrando en materia, muchas de las disposiciones anteriores fueron propuestas por mujeres combatientes y por mujeres víctimas, quienes se aseguraron de que los postulados tuvieran bases sólidas y sostenibles para garantizar su presencia y la equidad para todas (Esquit y García, 1998).

Uno de los principales compromisos de las mujeres desmovilizadas con el gobierno fue no volver a realizar actos de violencia contra la población, en espacial, no vulnerar los derechos de los niños y las niñas. Estas mujeres, líderes del cambio, garantizan la seguridad de los habitantes de la nación, actuando como receptoras y principales denunciantes ante cualquier movimiento extraño por parte de los exguerrilleros (Tobón et al., 2003).

El principio general de estos derechos son el cese al fuego, la dejación de armas, la terminación definitiva del conflicto con enfoque de género y la reincorporación a la vida civil, por lo cual se dan los siguientes pasos para el cumplimento: monitoreo y verificación. Con estas etapas, se fijan días específicos para la entrega y quedar en poder del gobierno nacional, con el fin de crear una estructura para cerrar el ciclo de la guerra (González, 2017). Después de esto, se adoptan los siguientes derechos como mecanismos de protección en el proceso de paz:

a. Igualdad y enfoque de género: Reconocimiento de las mujeres como ciudadanas autónomas, sujetos de derechos que, independientemente de su estado civil, relación familiar o comunitaria, tienen acceso en condiciones de igualdad con respecto a los hombres a la propiedad de la tierra y proyectos productivos, opciones de financiamiento, infraestructura, servicios técnicos y formación, entre otros. Todo ello, en atención a las condiciones sociales e institucionales que han impedido a las mujeres acceder a activos productivos y bienes públicos y sociales (Pascual et al., 2016). 
b. Regularización de la propiedad: Lucha contra la ilegalidad en la posesión y propiedad de la tierra. Garantía de los derechos de los hombres y las mujeres como legítimos poseedores y dueños de las tierras, de manera que no se vuelva a acudir a la violencia para resolver los conflictos relacionados con estas. Nada de lo establecido en el Acuerdo debe afectar el derecho constitucional a la propiedad privada (Trigueros, 1994).

c. Participación: La planeación, ejecución y seguimiento de los planes y programas se adelantarán con la activa participación de las comunidades, hombres y mujeres. El objetivo es garantizar la transparencia de la rendición de cuentas, la veeduría ciudadana y la vigilancia especial de los organismos competentes (Ibarra, 1972).

d. Democratización del acceso y uso adecuado de la tierra: Mecanismos y garantías que permiten que el mayor número posible de hombres y mujeres habitantes del campo sin tierra o con tierra insuficiente puedan acceder a ella. Se incentiva el uso adecuado de la tierra con criterios de sostenibilidad ambiental, de vocación del suelo, de ordenamiento territorial y de participación de las comunidades (Aguado, 1999).

e. Garantías para una reincorporación económica y social sostenible: Cada uno de los hombres y mujeres antes pertenecientes a las FARCEP, a partir de la terminación de las Zonas Verdes Transitorias de Normalización (en adelante ZVTN) y durante veinticuatro meses, recibirán una renta básica mensual equivalente al $90 \%$ del SMMLV, siempre y cuando no tengan un vínculo contractual que les genere ingresos (Tovar, 2004).

f. Garantías de no repetición: El Estado adoptará las medidas para garantizar el esclarecimiento del fenómeno paramilitar, evitar su repetición y garantizar el desmantelamiento de las organizaciones y conductas criminales responsables de homicidios y masacres, así como de la violencia sistemática, en particular, contra las mujeres. También desmantelará a quienes atenten contra los defensores de derechos humanos, contra los movimientos sociales o políticos, o 
quienes amenacen o atenten contra las personas que participen en la implementación de los acuerdos y la construcción de la paz (López y Hernandis, 2018).

g. Pacto político nacional: El anhelo del país de alcanzar una paz estable y duradera se funda en el reconocimiento de la necesidad de superar el conflicto armado. El gobierno nacional y el nuevo movimiento político que surja del tránsito de las FARC-EP a la actividad política legal se comprometen a promover un Pacto Político Nacional que involucre las regiones, los partidos y movimientos políticos, los gremios, las fuerzas vivas de la nación, la sociedad organizada, las comunidades en los territorios, los sindicatos, el Consejo Nacional Gremial y los diferentes gremios económicos, los propietarios y los directivos de los medios de comunicación, las iglesias, las confesiones religiosas, las organizaciones basadas en la fe y las organizaciones del sector religioso, la academia e instituciones educativas, las organizaciones de mujeres y de población LGBTI, las personas en condición de discapacidad, los jóvenes, las organizaciones de víctimas y de defensoras y defensores de derechos humanos, entre otros (Fisas, 2010).

h. Complementariamente se creará, por fuera de la Jurisdicción Especial para la Paz, un mecanismo judicial que será parte de la jurisdicción ordinaria y de la Fiscalía General de la Nación, en el cual una unidad especial decidirá lo necesario para su funcionamiento y la conformación de sus grupos de trabajo e investigación, con el fin de promover la participación efectiva de las mujeres.

Esta unidad tendrá autonomía para decidir sus líneas de investigación, llevarlas a la práctica y emprender actuaciones ante cualquier jurisdicción (Meneses, 2014), así como generar mecanismos efectivos de atención a los casos de prostitución forzada ocasionada en el conflicto armado interno.

Esta unidad tendrá como base de funcionamiento la articulación de un enfoque investigativo multidimensional, que se ocupe de toda la cadena criminal de las organizaciones y conductas objeto 
de su mandato, incluyendo las conductas criminales que afecten a mujeres, niñas, niños y adolescentes. También implementará planes metodológicos de investigación especializados respecto a los más graves hechos de victimización que las organizaciones y conductas objeto de este acuerdo lleven a cabo contra las mujeres, niñas, niños, adolescentes y población LGBTI.

i. Sistema Integral de Seguridad para el Ejercicio de la Política: Este sistema desarrollará un nuevo modelo de garantías de derechos ciudadanos y protección para los movimientos y partidos políticos, incluyendo el movimiento que surja del tránsito de las FARC-EP a la actividad política legal (Azkue, 2007).

j. Acuerdo de Participación Política: El gobierno nacional garantizará la participación en las altas instancias de los partidos y movimientos políticos, especialmente de aquellos que hayan sido afectados en su seguridad, de las organizaciones de víctimas y las de derechos humanos y movimientos sociales, incluidos los de las mujeres (de Paz Trueba, 2006).

Con el propósito de avanzar hacia la construcción de un modelo profesional y técnico del cuerpo de seguridad y protección, la Mesa Técnica hará las propuestas correspondientes al gobierno nacional, cuyo seguimiento y gestión serán adelantadas por el delegado presidencial. Esto incluye un sistema de formación y entrenamiento, de vinculación laboral y de seguridad social. El sistema contará con programas formativos en aspectos relacionados con la protección de las mujeres y de los riesgos específicos que ellas enfrentan (ASOTRANS, 2016).

k. Implementación de medidas integrales de seguridad y protección: En desarrollo de lo establecido en el subpunto 2.2.4 del acuerdo de Participación Política, el Programa Integral de Seguridad y Protección tendrá en cuenta, en la elaboración del Plan de Prevención y Protección, medidas contra la estigmatización, mecanismos de difusión amplia, campañas de legitimación y reconocimiento de los defensores y defensoras de derechos humanos (tanto 
en áreas rurales como urbanas), y la creación y difusión en medios de comunicación comunitarios y de interés público para temas relacionados con el impulso de los derechos humanos y la convivencia (Gherardi, 2006).

1. Protocolo de Protección para Territorios Rurales: El Ministerio del Interior creará un protocolo especial de protección para las comunidades rurales que fueron afectadas por el conflicto, el cual será concertado con las comunidades y organizaciones de cada territorio (incluidas las de mujeres) y con el Sistema Integral de Seguridad y Protección. Dentro de este protocolo, las comunidades rurales y sus organizaciones elaborarán su propio escenario de evaluación y definición de riesgos, el cual tendrá en cuenta las condiciones particulares de las mujeres (Mouly, 2016).

m. La producción y comercialización de drogas ilícitas y las economías criminales han tenido graves efectos sobre la población colombiana, tanto en el campo como en la ciudad. Esto ha afectado el goce y el ejercicio de sus derechos y libertades, de forma que las mujeres y jóvenes han sido afectados de forma particular por estas economías criminales (Humanas, 2017, p. 48).

n. Un enfoque diferencial de acuerdo con las condiciones de cada territorio: el Programa Nacional Integral de Sustitución de Cultivos de Uso Ilícito (en adelante PNIS) que se implemente debe tener un enfoque territorial y de género en los términos definidos en la Reforma Rural Integral (RRI) (punto 1), es decir, debe reconocer y tener en cuenta las necesidades, características y particularidades económicas, culturales y sociales de los territorios y las comunidades rurales, en especial, de las comunidades indígenas y afrodescendientes, y de las mujeres en estas comunidades y territorios, así como garantizar la sostenibilidad socioambiental (Calderón y Campos Ríos, 2013). El carácter participativo del PNIS permitirá elaborar diseños en consonancia con la especificidad y la naturaleza socioeconómica de los afectados (Decreto 896, 2017).

o. Fortalecer la participación y las capacidades de las organizaciones campesinas, incluyendo a las organizaciones de mujeres rurales 
para el apoyo (técnico, financiero, humano, etc.) de sus proyectos (Casares, 2002).

El PNIS promoverá la sustitución voluntaria de los cultivos de uso ilícito, mediante el impulso de planes integrales municipales y comunitarios de sustitución y desarrollo alternativo en el marco de la Reforma Rural Integral (RRI), diseñados en forma concertada y con la participación directa de las comunidades involucradas (Decreto 896, 2017).

p. Acuerdos con las comunidades: Un fundamento indiscutible de la solución definitiva al problema de los cultivos de uso ilícito se encuentra en el carácter voluntario y concertado y, por tanto, en la manifiesta voluntad de las comunidades de transitar caminos alternativos a los cultivos de uso ilícito. El compromiso del gobierno, por su parte, es el de generar y garantizar condiciones dignas de vida y de trabajo para el bienestar y buen vivir. Con el fin de formalizar ese compromiso y la decisión de sustituir los cultivos de uso ilícito, se celebrarán acuerdos entre las comunidades, el gobierno nacional y las entidades territoriales, antes de la puesta en marcha del programa en un territorio (Boer Cueva, 2015).

q. Construcción participativa y desarrollo de los planes integrales comunitarios y municipales de sustitución y desarrollo alternativo (PISDA): En consideración al carácter político, económico, social, ambiental y cultural del problema a enfrentar y a los efectos derivados de la falta de desarrollo en las zonas rurales, la economía ilegal y la violencia asociada a los cultivos de uso ilícito, se requiere la más amplia participación de las comunidades, para formular, ejecutar y hacer seguimiento a los PISDA, con lo cual se cumplen los objetivos del PNIS (Defensoría del Pueblo, 2017). Para este efecto y el fortalecimiento de la democracia local, el municipio y sus autoridades deberán jugar un papel protagónico junto a las comunidades.

r. Asambleas comunitarias: Con el fin de poner en marcha el proceso de planeación participativa de abajo hacia arriba, se apoyarán y fortalecerán las asambleas comunitarias, en las cuales habrá partici- 
pación efectiva de hombres y mujeres de la comunidad, y se crearán instancias de seguimiento a nivel municipal y de asambleas comunitarias (Boer Cueva, 2015).

s. $\quad$ Plan de formalización de la propiedad: Con el fin de promover el acceso a la tierra para hombres y mujeres y de incentivar el proceso de sustitución de los cultivos de uso ilícito en las áreas donde se cumplan los compromisos adquiridos por los cultivadores y cultivadoras con el PNIS, se acelerarán los procesos de formalización en los términos en que lo indica el Plan de Formalización Masiva de la propiedad del que trata el subpunto 1.1.5 de la RRI.

De acuerdo con lo expuesto, se identifica que el Sistema Integral tiene un enfoque diferencial y de género, que se ajusta y responde a las características particulares de las víctimas en cada territorio y cada población y, en especial, a las necesidades de las mujeres y de niños y niñas (Rojas, 2012). Dentro del proceso, se tienen en cuenta muchísimos más derechos para la mujer, lo que resulta de gran importancia y trascendencia, pues fueron postulados por mujeres y llevados hasta la etapa final del acuerdo de paz (Acosta et al., 2017).

Estas mujeres hacen historia, pues demarcan en sus vidas algo que años antes era solo un sueńo, pero hoy es una realidad. Lo mejor de todo es que la mujer fue escuchada y tomada en cuenta como debe ser: una tejedora de cambios sociales dispuesta a todo para hacer de su país un lugar mejor (Mateos, 2005).

\subsection{Reparación integral de víctimas}

En el contexto del conflicto armado, se presentan situaciones como el desarraigo, la muerte, el desplazamiento, las amenazas y demás atrocidades, dentro de un marco social en el cual la normalización se hace protagonista día a día. Después de los acuerdos de paz y del establecimiento de los mencionados artículos, se precede a la restitución de derechos de las mujeres víctimas del conflicto armado (Dumitrascu, 2018).

Desde el punto de vista de la Corte Interamericana de Derechos Humanos, debe existir un estándar esencial de reparación, que se enfoque en 
restituir de fondo aquellos derechos arrebatados a las víctimas de la guerra. Por medio de dicho estándar, se deben tener en cuenta distintos factores permanentes para garantizar el bienestar de las víctimas, porque todos los años que duraron en el conflicto no podrán ser recompensados con sumas exuberantes de dinero: los derechos no tienen valor económico (Cassinel, 2017). Dentro del sistema de la Corte Interamericana se encuentran tres factores importantes para obtener este fin:

1. Decisiones de fondo: Se trata de asociar directamente a los afectados por la violencia con el respeto, vincular a la víctima directamente con una tranquilidad social, que le permita desenvolverse como cualquier otro.

2. Decisiones judiciales: Es la actividad del Estado como ente protector, garantizando así un castigo para quienes vulneren los derechos de sus pares y ocasiones deterioro de la estructura del tejido social (...) (Hernández, 2016).

La iniciativa de estas mujeres trajó consigo muchos beneficios ya mencionados anteriormente; pero una parte importante es que, según el Código Penal, la reparación integral debe regirse sobre la responsabilidad civil del delito y no solo debe ser económica, también acarrea otros tipos de indemnizaciones que sean capaces de resarcir el daño a las víctimas. Es por esto que toma tanta relevancia el perdón y la reconciliación, pues estos dos pilares llevarán a la verdadera libertad. El papel del Estado es asegurar que, sea cual sea el mandatario, los derechos de las víctimas serán debidamente respetados sin importar el paso del tiempo (Plata Parada et al., 2015).

Estos derechos no conllevan oportunidades para finalizar el conflicto solamente, sino también garantizan la seguridad económica, física y psicológica de las víctimas y los victimarios (Quintero Cordero, 2020). Este programa hace parte del sistema integral de restitución, justicia, verdad y reparación, contemplado por el Proceso de Paz, un organismo autónomo que veló por la articulación de medidas de reparación con los demás mecanismos judiciales para que la paz pueda ser cumplida de forma transparente (Marín y González, 2017). 


\section{Conclusiones}

El proceso de paz y los mecanismos de protección internacional tienen bastante afinidad, ya que, en los distintos artículos del proceso de paz, se evidencia que la garantía y demás postulados son producto de los acuerdos anteriores a los que estaba sujeto nuestro país; por tanto, interactúan de gran manera con los fines del Acuerdo, el cual tiene como objeto el fin de la guerra que aqueja el país.

Es importante que mujeres y excombatientes hayan participado en la elaboración del Acuerdo actuando de manera objetiva y haciendo un análisis juicioso de lo que les convendría, ya que, la mayoría de los procesos de paz han sido liderados por hombres y han dejado de lado las opiniones y beneficios a los que las mujeres tienen derecho. Finalmente, el conflicto "tiene cuerpo de mujer”, porque ellas constituyen uno de los grupos más afectados y más comúnmente invisibilizados.

Como referente principal, todas las mujeres decidieron hablar y denunciar lo que les había ocurrido, lo cual contribuye a dar el primer paso para alejarse decisivamente del conflicto. Es evidente que hay que tener mucha fuerza para poder asumir un proceso tan difícil, después de que el acuerdo parecía una mera utopía para las mujeres cautivas, víctimas del conflicto.

Los mecanismos de protección y sistemas integrales son amplios, sin embargo, se espera que no se queden en acuerdos pactados y que se empiece una serie de cumplimientos de las partes, tanto víctimas como victimarios. Es de suma importancia reconocer que las falencias de muchas normas colombianas se llegan a ver no por falta de ser dictaminadas, si no por la negligencia en su cumplimiento (Mustafá Pabón, 2017) y la limitada legitimidad de la justicia (Corcione et al., 2019; Žilinčík, 2019).

Las mujeres víctimas de prostitución en etapa de conflicto no solo tuvieron que dejarlo todo, también las despojaron de lo único que se supone nadie puede arrebatarnos, la dignidad y la esperanza. Esto solo nos deja un punto claro: el proceso sin esta intervención no sería más que un acuerdo ceñido a las tradiciones sociales que nos acompañan desde siglos atrás. Sería retroalimentar una sociedad machista. Por el contrario, este proceso buscaba 
una equidad y logró demostrar que las mujeres valen, pueden, saben y son un ente fundamental para tejer una sociedad libre de guerra. Al final, solamente una cosa queda clara: una guerra que ha dejado tantas heridas abiertas puede ser curada con cuatro componentes fundamentales: diálogo, equidad, compromiso y respeto.

\section{Referencias}

Acosta, R. A., Brunet, M. A., y Laguna, J. C. (2017). La calidad de la información periodística de El Espectador.com. El caso del plebiscito por la paz, 2016 en Colombia. Revista Latina de Comunicación Social, 72, 1502-1514.

Aguado, A. (1999). Mujeres, regulación de conflictos sociales y cultura de la paz. Universitat de València.

Alacaldía Mayor de Bogotá. (2019). Programa Integral contra Violencias de Género. Sistema Orgánico Funcional Integral y Articulador para la protección a mujeres víctimas de violencias SOFIA. http://www.sdp.gov.co/sites/default/files/anexo_2_documento_base_ de_datos_sofia.pdf

Alcañiz Moscardó, M. (2009). La presencia de las mujeres en la resolución de los conflictos armados: mediación y capacitación. Informació Psicològica, 96, 43-53.

Almagro Iniesta, M. M. (2014). La desglobalización de la sociedad civil: los casos de Burundi y Liberia sobre los derechos de la mujer. Revista CIDOB D'Afers Internacionals, 105, 117-139.

Amnistia Internacional (2015). Los derechos de los trabajadores y trabajadoras sexuales son derechos humanos. Catherine Murphy, Policy Advisor at Amnesty International.

Asamblea General de las Naciones Unidas. (2002). Protocolo facultativo de la Convención de los Derechos del Niño relativo a la venta, la prostitución y pornografía infantil, 2000. ONU. https://www.ohchr.org/SP/ProfessionalInterest/Pages/OPSCCRC.aspx

ASOTRANS (2016). Pedagogía sobre el acuerdo gobierno FARC-EP. Programa de protección integral para las FARC-EP cuando se constituyan en partido o movimiento político. Boletín Informativo. https://www.asotrans.org/index.php/2016-08-23-14-31-33/boletin-informativo/item/219-pedagogia-sobre-el-acuerdo-gobierno-farc-ep-programa-de-proteccion-integral-para-las-farc-ep-cuando-se-constituyan-en-partido-o-movimiento-politico

Azkue, I. M. (2007). Género, rehabilitación posbélica y construcción de la paz. Hegoa.

Bermúdez-Tapia, M. (2012). Políticas públicas en materia penal sobre la atención de emergencias sociales. Gestión Pública y Desarrollo, 56(5), 21-24

Berrío, J. M. (2013). Las mesas de participación de víctimas: ¿una frustración más o un mecanismo de transformación social? Revista de Derecho Público, 31, 5-33. http://dx.doi. org/10.15425/redepub.31.2013.06

Betancur, C. B., y Cortés, A. F. M. (2011). Cuerpo, comercio sexual, amor e identidad. Significados construidos por mujeres que practicaron la prostitución. CES Psicología, 4(1), 32-51. 
Binstock, H. (1998). Hacia la igualdad de la mujer: avances legales desde la aprobación de la convención sobre la eliminación de todas las formas de discriminación contra la mujer. Repositorio Digital de la Cepal. https://repositorio.cepal.org/handle/11362/5865

Boer Cueva, A. R. (2015). En busca de la justicia transicional mediante el mantenimiento de paz. A gendered analysis. Relaciones Internacionales, 28, 105-128.

Bremer, J. J. (2017). Tiempos de guerra y paz. Los pilares de la diplomacia: de Westfalia a San Francisco. Editorial Taurus.

Cadavid, M. R. (2014). Mujer: blanco del conflicto armado en Colombia. Analecta Política, 4(7), 301-318.

Caicedo, L. P. (2008). Gravedad penal de la violencia sexual cometida en el marco del conflicto armado colombiano (Ponencia). https://humanas.org.co/archivos/humanas_documento_ pon_48Ponencia_Gravedad_penal_de_la_Violencia_Sexual.pdf

Calderón, Y. P., y Campos Ríos, G. (2013). Las mujeres jóvenes en México: ¿estudian o trabajan? Última Década, 21(39), 63-83.

Casado-Neira, D. C., y Pérez Freire, S. (2015). Sexo, masculinidades y las víctimas expiatorias. Las mujeres en contexto de prostitución en los medios: la mirada desde las ONG. Revista Internacional de Comunicación y Desarrollo (RICD), 1(2), 25-40.

Casares, A. M. (2002). Las mujeres y la "paz en la casa" en el discurso renacentista. Chronica Nova, 29, 217-244.

Casaús Arzú, M. E. (1999). Reflexiones en torno a la legitimidad del Estado, la nación y la identidad en el marco de los acuerdos de paz en Guatemala. Anuario de Estudios Centroamericanos, 25(1), 7-31. https://www.jstor.org/stable/25661310?seq=1

Cassinel, E. (2017). Colombia: un proceso de paz innovador. Enfoque de género. Cuadernos de Estrategia, 189, 203-208.

Castellanos, E., Ranea, B., y Burgos, I. (2013). Investigación sobre prostitución y trata de mujeres. Aprosers.

Castles, S. (2003). La política internacional de la migración forzada. Migración y Desarrollo, 1, 1-28.

Céspedes-Báez, L. M. (2017). En los Confines de lo Posible: inclusión del enfoque de género en el Acuerdo de la Habana. Utopía u oportunidad fallida. Análisis crítico del Acuerdo de Paz, 295-326.

Checa, F., y Acién, E. (2011). La actualidad del abordaje de la trata de personas para la prostitución forzada en Espańa. El plan integral y sus implicaciones para trabajadoras del sexo inmigradas. Gazeta de Antropología, 27(1).

Clark, K. (2001). Género, raza y nación: la protección a la infancia en el ecuador (1910-1945). En M. Moscoso (Comp.), Palabras del silencio: las mujeres latinoamericanas y su historia (pp. 219-256). Abya-Yala.

Convención de Belem do Para (1995). Convencion Interamericana Para Prevenir, Sancionar Y Erradicar La Violencia Contra La Mujer "Convencion De Belem Do Para”.

Corcione Nieto, M. A., Fernández-Osorio, A. E., Cabrera-Cabrera, L. J., \& Rojas Yaima, B. C. (2019). Aportes de la Academia a la legitimidad de la justicia en Colombia. Revista Cientifica General José María Córdova, 17(28), 819-843. https://doi.org/10.21830/19006586.516 
Cubides-Cárdenas, J., González, J., y Sierra-Zamora, P. (2017). Acceso a la justicia para mujeres víctimas de violencia y discriminación con enfoque de género en los precedentes del sistema interamericano. En A. J. Martínez (Ed.), Derechos económicos, sociales y culturales. Ediciones Nueva Jurídica.

Cubides Cárdenas, J. A., Sierra Zamora, P. A., Calixto Ortiz, D. A., y Pabón Caballero, N. (2019). Terrorismo por parte de las FARC-EP y políticas públicas orientadas a la seguridad nacional en Colombia durante 1990-2000. Revista Cientifica General José María Córdova, 17(26), 309-325. https://doi.org/10.21830/19006586.404

Daich, D. (2012). ¿¿Abolicionismo o reglamentarismo? Aportes de la antropología feminista para el debate local sobre la prostitución. Runa, Archivo para las Ciencias del Hombre 33(1), 71-84. https://doi.org/10.34096/runa.v33i1.340

De Paz Trueba, Y. E. (2006). Beneficencia, control social y disputas de las mujeres en el espacio público del sur bonaerense a fines del siglo XIX y principios del XX. Temas de Historia Argentina y Americana, 9, 143-164.

Defensoría del Pueblo (2017). Análisis de la fase inicial de diseño e implementación del Programa Nacional de Sustitución de Cultivos de Uso Ilícito. https://verdadabierta.com/wp-content/ uploads/2018/11/Informe-PNIS-2017-para-web-1.pdf

Dumitrascu, A. (2018). Las mujeres en MENA: empoderamiento para la paz. Boletín IEEE, 12, 343-359.

Durango Álvarez, G. A. (2012). Los movimientos sociales desde la perspectiva de las mujeres y pueblos indígenas: un análisis desde la jurisprudencia de la Corte Constitucional colombiana. Revista de Derecho, 37, 111-130.

Esquit, E., y García, I. (1998). El derecho consuetudinario, la reforma judicial y la implementación de los acuerdos de paz. FLACSO, Programa Guatemala.

Fisas, V. (2010). El proceso de paz en Colombia. Quaderns de Construcció de Pau, 17(7), 1-24.

Garavito, A., Iregui, A. M., y Ramírez, M. T. (2012). Inversión extranjera directa en Colombia: evolución reciente y marco normativo. Borradores de Economía, 713, 1-64. https://www. banrep.gov.co/es/node/27981

Garay Acevedo, C. P., y Pérez Guecha, A. del P. (2018). Los derechos humanos en Colombia. Revista Cientifica General José María Córdova, 16(23), 83-105. https://doi. org/10.21830/19006586.307

Garbay, S. (2004). Migración, esclavitud y tráfico de personas [artículo]. Repositorio de la Universidad Andina Simón Bolívar. http://hdl.handle.net/10644/616

Gherardi, N. (2006). Notas sobre acceso a la justicia y servicios jurídicos gratuitos en experiencias comparadas: ¿un espacio de asistencia posible para las mujeres? En $\mathrm{H}$. Birgin, y B. Kohen (Comps.), Acceso a la justicia como garantía de igualdad. Instituciones, actores y experiencia comparada. Editorial Biblos.

Gómez Suárez, L. N., David, D., y De Jesús, C. (2017). Las normas y políticas públicas para la mujer emprendedora en el contexto del postconflicto. Repositorio de la Universidad Católica Luis Amigo. http://repository.ucatolicaluisamigo.edu.co:8080/jspui/bitstream/ucatolicaamigo/69/2/Fulam_mujer.pdf 
González, M. F. (2017). La "posverdad” en el plebiscito por la paz en Colombia. Nueva Sociedad, 269, 115-126.

Grau, M. (2013). Recordar para olvidar la desigualdad de género. Revista de Derecho Público, 31, 2-33. https://doi.org/10.15425/redepub.31.2013.11

Guío Camargo, R. E. (2009). El concepto de familia en la legislación y en la jurisprudencia de la Corte Constitucional colombiana. Studiositas, 4(3), 65-81.

Güiza Suárez, L., Rodríguez-Barajas, C. D., Ríos Osorio, B. O., y Moreno Gallo, S. S. (2016). Género y empoderamiento comunitario en un contexto de posconflicto: el caso de Vergara, Cundinamarca (Colombia). Estudios Socio-Jurídicos, 18(2), 117-147. http:// dx.doi.org/10.12804/esj18.02.2016.04

Heim, D. (2011). Prostitución y derechos humanos. Cuadernos Electrónicos de Filosofía del Derecho, 23, 234-251.

Hernández, R. P., y Gras, R. M. L. (2005). Víctimas de violencia familiar: Consecuencias psicológicas en hijos de mujeres maltratadas. Anales de Psicologia/Annals of Psychology, 21(1), 11-17.

Hernández, L. (2016). Rojas y violetas: relacionamiento entre mujeres farianas y las organizaciones Sisma Mujer y Ruta Pacifica de las Mujeres en el marco de los diálogos de paz [Tesis doctoral]. Universidad del Rosario.

Humanas Colombia. (2017). Equidad de género y derecho de las mujeres. El acuerdo final para la paz. https://www.humanas.org.co/alfa/dat_particular/ar/ar_7354_q_Equidad-GeneroMujeres-Acuerdo-final-1-1.pdf

Ibáñez, A. M., y Querubín, P. (2004). Acceso a tierras y desplazamiento forzado en Colombia. Documento Cede, 23, 1-114.

Ibarra Melo, M. E. (2011). Acciones colectivas de las mujeres en contra de la guerra y por la paz en Colombia. Sociedad y Economía, 13, 66-86.

López, J. G., y Hernandis, C. V. (2018). Impulsando el protagonismo de las mujeres en el proceso de paz de Colombia. Ciencia, Técnica y Mainstreaming Social, (2), 125-133.

Marín, P. R., y González, L. R. (2017). La vulnerabilidad de la mujer en la guerra y su papel en el posconflicto. El Ágora USB, 17(1), 290-308. https://doi.org/10.21500/16578031.2827

Mateos, O. (2005). Angola: el complejo camino hacia la paz. Nova África, 16, 11-21.

Meneses, J. E. (2014). Gestando la paz, haciendo memoria: iniciativas locales de construcción de paz en Colombia desde la perspectiva de las mujeres. ONU Mujeres.

Mesa, M. (2014). Por un futuro de paz en Colombia: incorporando las propuestas de las mujeres. Anuario CEIPAZ, 7, 219-244.

Meertens, D. (1995). Mujer y violencia en los conflictos rurales. Análisis político, (24), 36-50.

Mesa, M. (Ed.). (2006). La cooperación al desarrollo y la construcción de la paz (Vol. 142). Cáritas Espańola.

Mouly, C. (2016). Mesas de concertación y seguimiento de los acuerdos de paz en Guatemala: lecciones aprendidas para la paz territorial en Colombia. Revista CS, 19, 115-140.

Mustafá Pabón, A. H. (2017). El sector privado y la construcción de paz en Colombia: la mujer, un actor clave en la sostenibilidad de la paz [Tesis de pregrado]. Pontificia Universidad Javeriana. 
Naciones Unidas (2014). Los derechos de la mujer son derechos humanos. Nueva York, Ginebra. pp. 1-130. https://www.ohchr.org/Documents/Publications/HR-PUB-14-2_SP.pdf

Niño, M. B. (2017). Aspectos novedosos de la participación política de las mujeres en el proceso de paz con las FARC-EP. Cuadernos de Estrategia, 189, 209-220.

Oficina del Alto Comisionado para la Paz. (2016). Acuerdo final para la terminación del conflicto y la construcción de una paz estable y duradera. http://www.altocomisionadoparalapaz.gov. co/procesos-y-conversaciones/acuerdo-general/Paginas/inicio.aspx

ONU (1951). Convenio para la represión de la trata de personas y de la explotación de la prostitución ajena. Adoptado por la Asamblea General en su resolución 317 (IV), de 2 de diciembre de 1949.

Olaya, M. A. (2004). El bloque de constitucionalidad en la jurisprudencia de la Corte Constitucional colombiana. Precedente. Revista Jurídica, (-), 79-102. https://doi. org/10.18046/prec.v0.1406

Palacios Gómez, J. L. P. (2001). Las técnicas cualitativas de investigación social en la medición de la calidad de los servicios públicos: una aproximación teórica y metodológica. Barataria: revista castellano-manchega de ciencias sociales, (4), 85-100.

Pascual, C. P., Pinedo, I. A., Grandes, G., Cifuentes, M. E., Inda, I. G., y Gordon, J. P. (2016). Necesidades percibidas por las mujeres respecto a su maternidad. Estudio cualitativo para el rediseño de la educación maternal. Atención Primaria, 48(10), 657-664. http://dx.doi. org/10.1016/j.aprim.2015.12.004

Pérez Sauceda, J. B. (2015). Cultura de paz y resolución de conflictos: la importancia de la mediación en la construcción de un estado de paz. Ra Ximhai: Revista Cientifica de Sociedad, Cultura y Desarrollo Sostenible, 11(1), 109-131.

Pinzón Paz, D. C. (2009). La violencia de género y la violencia sexual en el conflicto armado colombiano: indagando sobre sus manifestaciones. En J. A. Restrepo, y D. Aponte (Eds.), Guerra y violencias en Colombia: herramientas e interpretaciones. Editorial Pontificia Universidad Javeriana; Centro de Recursos para el Análisis de Conflictos.

Plata Parada, A. M., Arévalo Moreno, P. A., y Prada Acosta, F. A. (2015). Análisis de contenido de columnas y editoriales de opinión, del Tiempo y El Espectador, acerca de los primeros tres acuerdos entre el gobierno de Juan Manuel Santos y la guerrilla de las FARC en el proceso de paz de La Habana [Tesis de pregrado]. Universidad de La Sabana.

Rojas, C. (2012). La dimensión no tan conocida: el enfoque de género como una herramienta para analizar la construcción de paz. Construcción de Paz en Colombia, 437-461. En: Rettberg, A. (2012). Construcción de paz en Colombia. UNIANDES.

Quintero Cordero, S. P. (2020). Seguridad ciudadana y participación de las comunidades en América Latina. Revista Científica General José Maria Córdova, 18(29), 5-24. https://doi. org/10.21830/19006586.561

Sieder, R., y Sierra, M. T. (2011). Acceso a la justicia para las mujeres indígenas en América Latina. CMI Working Paper, WP2011:2. https://www.cmi.no/publications/3941-acceso-a-la-justicia-para-las-mujeres-indigenas-en

Sierra-Zamora, P. A. (2018). La tutela de los Derechos Humanos en situaciones de postguerra: el caso colombiano [Documento de trabajo]. https://doi.org/10.17605/OSF.IO/7KM83 
Sierra-Zamora, P. A., y Jiménez-Barrera, L. V. (2019). Genealogía de la tortura en Colombia: una mirada desde los derechos humanos. Revista Novum Jus, 13(2), 1-14.

Sistema Único de Información Normativa (2017). DECRETO 896. Por el cual se crea el Programa Nacional Integral de Sustitución de Cultivos de Uso Ilícito (PNIS). http:// www.suin-juriscol.gov.co/viewDocument.asp? ruta=Decretos/30030680

Tirado Acero, M. (2011). El debate entre prostitución y trabajo sexual: una mirada desde lo socio-jurídico y la política pública. Revista de Relaciones Internacionales, Estrategia y Seguridad, 6(1), 127-148.

Tobón Olarte, G., Martínez Giraldo, M. E., López Céspedes, M. I., Vélez, C., Ballén, G., y Puyana Villamizar, Y. (2003). El tiempo contra las mujeres: debates feministas para una agenda de paz. Zona Visual

Tokatlian, J. G. (2001). Colombia, el Plan Colombia y la Región Andina. Nueva Sociedad, 173, 126-143. https://nuso.org/articulo/colombia-el-plan-colombia-y-la-region-andina-implosion-o-concertacion/

Tomàs, J. (2008). ¿ Nuevas estrategias para viejas esperanzas? Escepticismo y paciencia en el proceso de paz de Casamance. Nova África, 99-116. https://repositorio.iscte-iul.pt/bitstream/10071/7209/1/07NA22.Tomas99-116-1.pdf

Torrijos Rivera, V., y Abella Osorio, J. D. (2018). El comportamiento de las FARC tras la firma de los acuerdos de La Habana. Revista Científica General José María Córdova, 16(24), 31-60. https://doi.org/10.21830/19006586.342

Tovar, P. (2004). Familia, género y antropología. Tabula Rasa, 1(2), 323-326.

Trigueros, P. (1994). Unidades domésticas y función de la mujer en un poblado rural en el que se practica la emigración a Estados Unidos. En S. Vania y E. Mc Phail (Coords.), Nuevos textos y renovados pretextos. Colegio de México. https://doi.org/10.2307/j.ctv4w3tg7.9

Varón-Mejía, A., Londoño-Toro, B., y Luna de Aliaga, B. (2012). El delito de trata de personas: hacia la aplicación de estándares internacionales para la prevención, judicialización, protección y asistencia integral a las víctimas en Colombia. Revista de Derecho, 37, 198-230

Vela Caro, A. C. (2015). Del concepto jurídico de familia en el marco de la jurisprudencia constitucional colombiana: un estudio comparado en América Latina [Tesis de pregrado, Universidad Católica de Colombia]. Semantics Scholar. https://pdfs.semanticscholar. org/8d82/dc8a58ebe30f423c49d3b6559c3d69be5783.pdf

Wilson, M. S. (1999). Mujer y derechos humanos. Instituto de la Mujer.

Žilinčík, S. (2019). La atribución pública como reguladora de emociones. Revista Cientifica General José María Córdova, 17(28), 869-889. https://doi.org/10.21830/19006586.528

Zuluaga-Sánchez, G. P., y Arango-Vargas, C. (2013). Mujeres campesinas: resistencia, organización y agroecología en medio del conflicto armado. Cuadernos de Desarrollo Rural,10(72), 159-180. 


\section{Instrumentos jurisprudenciales}

Colombia, Congreso de la República. (2005). Ley 985 De 2005. Medidas de Protección contra la Trata.

Colombia, Constitución Política. (1991). Artículo 17. Derechos Fundamentales.

Colombia, Constitución Política. (1991). Ley 1235 Del 2008. Garantías A Víctimas Del Conflicto.

Colombia, Corte Constitucional. (2008). Auto 098. M.P Manuel José Cepeda Espinosa.

Colombia, Corte Constitucional. (2008). Auto 251. M.P Manuel José Cepeda Espinosa.

Colombia, Corte Constitucional. (2013). Auto 098. M.P Luis Ernesto Vargas Silva.

Colombia, Corte Constitucional. (2002). Sentencia C-385. M.P Jaime Araujo Rentería.

Colombia, Corte Constitucional. (2010). Sentencia T-629. M. P. Juan Carlos Henao Pérez.

Colombia, Corte Constitucional. (2015). Sentencia T-736. M. P. Gloria Stella Ortiz Delgado.

Constitución Política de Colombia. (1991, julio 20). Gaceta Constitucional n. ${ }^{\circ} 116$. http://bit. ly/2NA2BRg

Corte Interamericana de Derechos Humanos (2018). a Convención Interamericana para Prevenir, Sancionar y Erradicar la Violencia contra la Mujer. Convención de Belem do Para. 